\title{
Developing emotional intelligence and situational awareness through simulation coaching
}

\author{
Mari Helena Salminen-Tuomaala* \\ Seinäjoki University of Applied Sciences, School of Health Care and Social Work, Finland
}

Received: April 5, 2020

DOI: $10.5430 / \mathrm{cns} . v 8 \mathrm{n} 2 \mathrm{p} 13$

Accepted: May 11, 2020

Online Published: May 13, 2020

URL: https://doi.org/10.5430/cns.v8n2p13

\begin{abstract}
Objective: To examine how simulation coaching affects emotional intelligence (EI) skills and situational awareness in social and healthcare staff of small and medium-sized enterprises.

Methods: This qualitative study involved 36 mental health and child protection professionals in five enterprises. Following simulation-based coaching interventions centered around the development of EI and situational awareness, the participants wrote essays on their development. Inductive content analysis was used to analyze the body of material.

Results: The participants found simulation coaching an effective method for learning EI, situational awareness and teamwork skills. They also considered the scenarios and shared reflections to be a form of work supervision.

Conclusions: Simulation coaching offers potential for the development of EI and situational awareness in mental health and child protection professionals.
\end{abstract}

Key Words: Emotional intelligence, Simulation coaching, Situational awareness

\section{INTRODUCTION}

The context of this study is an extensive research and development project, carried out in Finland in the years 2016-2020 and assisted by the European Social Fund. The aims of the overall project were threefold: (1) to create a multiprofessional simulation-based coaching program for health and social care professionals in small and medium-sized enterprises in one region in Finland; (2) to create a network of simulated learning environments in the same region; and (3) to develop multiprofessional simulation education for medical and nursing students representing the same region. The project brought together two educational institutions, a health technology development centre as well as a significant number of public and private health and social service providers in the region.
This qualitative study is connected to the first project area mentioned above, or the creation of a simulation-based coaching program (2017-2019) for health and social care professionals in small and medium-sized enterprises (SMEs). The SMES were private business organizations. In all, the participants were 213 professionals in 20 private enterprises, originally recruited by telephone contacts. The companies operate in various areas, including child protection, mental health services, geriatric care and disability services. The aim of the coaching was to increase participants' theoretical and practical competence based on a learning needs assessment. The coaching program involved 160 simulation-based sessions, provided to 213 participants in cooperation between the regional University of Applied Sciences and Vocational Education Centre. Simulation-based coaching/simulation coaching refers to an approach in which the teacher is seen

\footnotetext{
* Correspondence: Mari Helena Salminen-Tuomaala; Email: Mari.Salminen-Tuomaala@ seamk.fi; Address: Seinäjoki University of Applied Sciences, School of Health Care and Social Work, Finland.
} 
as a coach, whose main task is to support and encourage the professionals participating in a continuous professional development.

This study deals with a sub-group of the professionals working in small and medium-sized enterprises. The participants were 36 mental health and child protection professionals in five of the 20 private enterprises. In the initial learning needs assessment, these professionals had listed learning needs associated with the development of emotional intelligence (EI) and situational awareness. The study aims to describe how the professionals experienced the simulation-based coaching.

\section{The research question was:}

"How does simulation coaching affect EI skills and situational awareness in social and healthcare staff of small and medium-sized enterprises?"

The participants mostly represented small enterprises with a low number of staff members. Working in relatively sparsely populated areas, where an increasing proportion of the care providers are aged, they struggle to compete with national and international chains and to keep up with the latest evidence-based practice and technology. The simulationbased coaching program described in this paper was preceded by a Web-based needs assessment and careful planning of the training to tailor it to participant needs.

The main responsibility for the development of the simulation coaching concept described in this paper lay with the department responsible for nursing and social work education at a University of Applied Sciences, together with a Vocational Education Centre. This University is a multi-disciplinary educational institution responsible for Bachelor and Master level education in the region. It is also nationally and internationally active in research, development and innovation, including the development of health and social care education and entrepreneurship. The study options include degree programs in nursing, public health nursing, physiotherapy, elderly care, social work and international business, among others. ${ }^{[1]}$ The Vocational Education Centre provides upper secondary level vocational education and training, including a 2-3-year practical nursing program. ${ }^{[2]}$

This introduction is followed by a Literature Review, in which a theoretical framework is constructed around the following concepts: emotion, EI, situational awareness, situational sensitivity, simulation pedagogy and simulation coaching. The Methodology section looks at research ethics and explains how the qualitative data was collected and analyzed. Three main categories of Findings are presented. The paper ends with a Discussion, followed by the implications of the findings for future education in the Conclusions section.

\section{Literature REVIEW}

\subsection{Emotion and emotional intelligence}

A dictionary definition of emotion is:

"1) a conscious mental reaction (such as anger or fear) subjectively experienced as strong feeling usually directed toward a specific object and typically accompanied by physiological and behavioral changes in the body, 2) a state of feeling and $3)$ the affective aspect of consciousness: feeling. Synonyms for emotion: chord, feeling, passion, sentiment." [3]

To put it shortly, emotions are subjective, and they have a physiological and an expressive (behavioral) component. ${ }^{[4,5]}$

The term EI became widely known in the 1990's through the work of two psychologists, Saloney and Mayer. The concept is based on previous research on (social) intelligence and emotion-related skills. ${ }^{[6]}$ EI can be conceptualized in two ways; it can be approached using an ability EI model or a trait EI model. ${ }^{[7]}$ One definition of EI is:

"the ability to recognize and manage one's emotions, to recognize other people's emotions and to use this information to guide one's thinking and action." ${ }^{[8]}$

According to Lievers, ${ }^{[7]}$ in this type of models, EI is seen as an ability or a type of intelligence that can be measured through performance-based tests. In this paradigm, EI is viewed as another legitimate type of intelligence. Four levels of EI were proposed by Salovey, Brackett and Mayer. At the lowest level, a person is able to accurately perceive emotions, including those expressed through non-verbal communication. One step higher from just perceiving emotions means that a person is able to reason using emotions and use emotions to assist thinking. This involves, for example, that one names, analyses and anticipates emotions, or uses them to facilitate prioritization. At the second highest level, a person is capable of analyzing and understanding emotions, or perceiving and interpreting various causes or meanings carried by emotions. The highest level of EI refers to conscious, reflective management or regulation of emotions. ${ }^{[7,8]}$ An EI test has been developed to measure EI with help of various ability tasks. ${ }^{[9]}$

An example of a well-known trait EI model, named emotional-social intelligence model, comes from Bar-On, ${ }^{[10]}$ who has been interested in the traits, skills and behavioral patterns underlying emotional and social intelligence. These types of models see EI as akin to personality. ${ }^{[7]}$ To quote Bar-On:

"emotional-social intelligence is a cross-section of interrelated emotional and social competencies, skills and facilitators that determine how effectively we understand and 
express ourselves, understand others and relate with them, and cope with daily demands." [10]

His model has five components or broad factors including intra - and interpersonal skills, adaptability, general mood and stress management. The five factors consist of 15 further facets. Examples of intrapersonal facets involve selfregard and emotional self-awareness, whereas interpersonal facets include empathy, for instance. Adaptability has to do with reality testing, flexibility and problem-solving. ${ }^{[7]}$ Looking at the model the implication is that intelligence alone is not sufficient; an emotional component is necessary for self-regulation, social relationships and effective performance in general. This model is connected with a selfreport measure, although a multirater version of the measure has also been developed. ${ }^{[11]}$ It should also be mentioned that the two constructs, EI and social intelligence, seem to be overlapping. EI can either be seen as the narrower concept focusing on emotional problems embedded in social problems, or as the broader construct that includes internal processes/emotions. ${ }^{[7]}$

Despite what has been said about the trait/ability distinction, according to a literature review conducted by Cherniss, ${ }^{[11]}$ several relatively uniform definitions of EI exist, although models and measures (such as self-reports, ability tests, multirater instruments) of EI may be conflicting. According to Cherniss, most researches have accepted a basic definition by Mayer et al. from 2000:

"the ability to perceive and express emotion, assimilate emotion in thought, understand and reason with emotion, and regulate emotion in the self and others."[12]

Besides psychology, EI has gained momentum within social and health sciences, education and practice. In spite of the complexity and ambiguity of the concept, much of the research seems to suggest that EI can be learnt and taught. ${ }^{[13-20]}$ For example, professional growth in the area of EI is commonly seen to be an essential element of nursing competence. $^{[15]}$ EI is thought to help understand the needs and emotions of patients. ${ }^{[21,22]}$ On the other hand, it can be useful in decision-making and problem-solving. ${ }^{[22]}$ It has been suggested that EI can also facilitate team cohesion and stress management. ${ }^{[14,23]}$ It also seems to be widely accepted that this kind of professional growth can be attained with help of critical reflection. ${ }^{[16]}$

To give two recent examples of training on EI: A study conducted with nursing students, using the Trait Emotional Intelligence Questionnaire - Short Form (TEIQue-SF) did not show any significant improvement in the participants' EI following training on EI, reflective discussions, journaling, and

Published by Sciedu Press other reflective writing connected with a service project. ${ }^{[24]}$ In contrast, another study demonstrated significant self- and client-rated benefits of EI training for a group of aged care workers, compared to a control group. The training involved discussion and reflection on EI-related constructed as proposed by Bar-On. The training was found to have positively affected participants' wellbeing, psychological empowerment and care quality. ${ }^{[20]}$

To sum up: since EI is a complex concept, there has been much discussion on how it could be defined and measured, and on what kind of training might be useful to develop EI. In addition to self-reports and performance tests, it has been suggested that interviews, peer reports and situational judgment tests (SJTs) could be used to measure constructs like EI. SJTs are low fidelity simulations, in which participants are faced with job-related situations and sets of alternate courses of action. ${ }^{[7]}$ Finally, it should be mentioned that as a further development, the concepts of team and collective intelligence are gaining popularity. Team intelligence can be seen as a result of successful collaboration between individuals. ${ }^{[25]}$

\subsection{Situational awareness}

Situation or situation awareness (SA) is an old concept, although the term has become generally known relatively recently. A well-known definition comes from Endsley:

"Situational awareness is defined as the perception of the elements in the environment in a volume of time and space, the comprehension of their meaning and the projection of their status in the near future."[26]

In other words, while continuously selecting and processing information, a person perceives and seeks to comprehend what is occurring in the environment. In the ideal case, the person can make an informed guess about how the situation will evolve and what implications that will bring. It is generally accepted that the role of SA becomes emphasized in high risk and high stress situations. ${ }^{[27]}$ This notion is reflected in another definition of SA from 1990's:

"up-to-the minute comprehension of task relevant information that enables appropriate decision making under stress.”[28]

$\mathrm{SA}$ is dynamic and iterative; the perceptions and interpretations in a given situation must be constantly updated. ${ }^{[29]}$ Failing in SA can affect care decisions and pose risks to client and patient safety. ${ }^{[30,31]}$ Besides existing at an individual level, SA can be claimed to be occur at team and organizational levels. ${ }^{[27,32]}$

Although SA has been commonly linked with emergency nursing and similar contexts, the concept can be argued to be linked with other client and patient situations as a contributor 
to patient and client safety. For example, simulation-based SA training was successfully incorporated in an undergraduate medical students' program. ${ }^{[33]}$

\subsection{Simulation pedagogy}

Simulation-based learning is another concept relevant to this paper. In simulation pedagogy, the aim is to offer participants as authentic learning experiences as possible. Besides concrete, guided practicing in real or nearly-authentic contexts, simulation pedagogy makes use of collaborative learning and shared reflection. Carefully planned scenarios based on explicit learning aims make it possible for learners to gain concrete experiences of various client or patient situations, and to try out alternative action. Learners' experiences can become personally very meaningful in a real or reality-based context. ${ }^{[34]}$

A systematic review, whose purpose was to summarize outcomes of technology-enhanced simulation training for health professionals, revealed that when compared with no intervention, simulation training had a significant effect on learners' skills, knowledge and professional behavior, as well as moderate effects for patient-related outcomes. ${ }^{[35]}$ In nursing, simulation is a well-established pedagogy. ${ }^{[36]}$ Compared to standard practical training periods in a clinical setting, simulationbased learning may even result in more profound learning experiences, because it always combines action-based learning, reflection and feedback from the teacher and peers. ${ }^{[37]}$ Besides clinical skills, simulation has been proved effective in learning such non-clinical skills as problem-solving, critical thinking, and decision-making. ${ }^{[38]}$ Importantly from the perspective of this paper, simulation has also been considered useful for the development of EI and situational awareness. ${ }^{[39,40]}$ Some investigators remind us that besides simulated scenarios focusing on specific physical or psychological problems, holistically focused scenarios should be created, in which the patient or client is primarily seen as a unified whole being. [41]

When continuing education is provided to practicing professionals, as in this project, an approach that stresses coaching, rather than teaching, can be effective. The teacher or facilitator is seen as a coach, whose task is to support and encourage professionals interested in further competence development. ${ }^{[2,43]}$ The facilitators must be well trained to be able to detect knowledge gaps and guide the reflection of the learning experience. ${ }^{[44,45]}$ Secondly, in learning non-clinical skills, the role of the client or patient in a scenario is essential. In some scenarios it might not make much difference, whether a manikin or a real person takes on the role of the client. However, when the aim is to study and develop participants' EI or situational awareness, it is advisable to have a facilitator playing the client or patient role.

\section{Methodology}

This qualitative study is part of a larger research and development project, as described in the Introduction. The study is associated with a sub-project, which aimed at creating a multiprofessional simulation-based coaching program for health and social care professionals in small and medium-sized enterprises. In this study, the research question was to explore how the simulation coaching had affected the participants' EI skills and situational awareness. The analysis is based on short essays written by the participants.

\subsection{Participants and data collection}

The target group represented five enterprises in mental health and child protection (foster care) services. They held a Bachelor's degree or equivalent in nursing $(n=30)$ or social services $(n=6)$, and there was an equal number of men and women. The participants' principal tasks were guide and support their clients' mental health, general growth and education. When enquired about their continuing learning needs, these participants listed EI, empathy skills and situational awareness.

Based on the participant needs, simulation-based coaching interventions centered around the development of EI and situational awareness were implemented in the five enterprises' own facilities ( $n=36)$, mainly in multiprofessional groups. Scenarios were planned based on the following themes: (1) The development of social intelligence and high quality interaction; (2) Awareness of one's emotions in relation to other people's emotions; (3) Regulating one's emotions and becoming aware of other people's emotions. Before the scenarios, the concepts of EI and SI were discussed based on the various definitions and models.

Each scenario lasted approximately 20 minutes and was followed by a one-hour feedback discussion. The sessions were led by two teachers, called coaches, selected based on their expertise in the topic. Participants were assigned carefully constructed challenging roles. At the onset of the scenario, they were only briefed about the initial situation and requested to respond to the situation at hand. One of the coaches portrayed the role of the client. For example, the coach played the role of a child or youngster displaying challenging behavior, while two participants worked together, looking for a constructive response. The other participants observed the management of the situation, especially concentrating on EI and situational awareness. In one simulated scenario, a frustrated young girl (a coach) acted out her aggression by throwing a kicking and screaming temper tantrum. The pair of nurses reacted by expressing 
understanding and setting limits on the child's uncontrolled behavior. In the feedback discussion following the scenario, the participants worked out methods for developing interaction and social intelligence and discussed relevant domains of professional growth.

One or two simulation days were arranged in each enterprise. It was decided that three scenarios per day was a suitable number, because acting out the roles could be an intense, sometimes a demanding experience. The simulation coaching concept also included a temperament test for the participants. ${ }^{[46]}$ The results of the test were known only to the participants themselves, and they were asked to compare the results to their experiences of EI during the simulation training.

At the end of the simulation day, directly following the last feedback discussion, all participants were asked to write short essays about their learning experiences. They were instructed to describe how the simulation scenarios had affected their professional competence, EI and situational awareness.

\subsection{Data analysis}

Inductive content analysis was used to analyze the body of material. The research was undertaken with an interpretive paradigm. In other words, the aim of the analysis was to capture and interpret meanings attached by participants to the simulation coaching situation, which was seen as a symbolically constructed concept. The transcribed data was first read through a few times. All units of thought or clauses that seemed to relate to the research question where picked out, written in Word files and then rewritten as reduced expressions. Attention was paid to retain the core thoughts or ideas contained in the original expressions. After this, reduced expressions were grouped into categories according to their content. These categories were grouped under higher order headings and finally collapsed into main categories. The original data was consulted repeatedly in order to solidify the interpretation. ${ }^{[47]}$

The main categories were: (1) Social intelligence and Placing Oneself in Other People's Position; (2) Awareness of One's Emotions and Expressing Emotions, and (3) Emotional Intelligence and Situational Awareness. The first main category: (1) consisted of the following lower order categories: interpretation of verbal and non-verbal interaction; provision of constructive feedback, and appreciation of dialogic interaction. The second main category (2) included three subcategories: recognition of positive and negative emotions; naming unpleasant emotions, and the importance of exchanging experiences of emotions. Last, the third main category (3) consisted of four sub-categories: different emotions resulting Published by Sciedu Press from the same situation; reading and respecting another person's emotional state; considerate attitude towards various emotions, and being aware of the importance of emotions for the collective atmosphere.

\subsection{Research ethics}

The topic was selected based on the understanding that although simulation pedagogy is widely used and encouraged, there is still a limited body of knowledge of the effect simulation-based training can have on EI and SA. The results can be useful for planners of continuing multiprofessional simulation-based education for social and healthcare professionals.

Guidelines on good scientific practice and ethical research principles were followed carefully during the research process. ${ }^{[48]}$ Participation was voluntary and the essays were written anonymously. ${ }^{[49]}$ The researchers gave some thought to reflexivity, or potential bias; the effect their background might have had on the analysis. ${ }^{[50]}$ The team of investigators involved in this study had themselves taught simulationbased courses. Their pre-understanding and expectations may have affected the findings in some manner, but most probably also facilitated the analysis. The investigators strove for a data-driven analysis to their best ability. ${ }^{[51]}$ The method selected served well the purposes of this study and increased its credibility, and the careful analysis and reporting enhanced its confirmability. Finally, the research team considered the transferability of the concepts and findings to other target groups and settings. ${ }^{[50]}$ This is discussed briefly in the Conclusions section.

\section{Results}

\subsection{Social intelligence and placing oneself in other peo- ple's position}

Respondents found that scenario 1, centered around the theme of social intelligence and interaction, had made them better prepared to understand people's opinions and perspectives, to relate to their experiences and to place themselves in their position. They felt that their conversation skills, listening to others and ability to provide feedback had improved. They also felt more courageous about expressing their opinions. Respondents became better aware of the importance of genuine presence, which could increase their concentration in interaction, both verbal and non-verbal. They reflected on how to give feedback in an empathetic and encouraging manner. On the other hand, the feedback discussions following the scenarios had also opened up an opportunity to openly discuss issues which had often been neglected or avoided in routine daily work. Finally, simulation was considered to be a suitable tool for the supervision of work. According to the 
respondents, simulation-based scenarios could increase team intelligence and wellbeing at work.

\subsection{Awareness of one's emotions and expressing emo- tions}

Scenario 2 dealt with participants' awareness of their emotions. According to the respondents, this scenario had helped them find what they called "mirrors" for their thoughts in other people. The roles, combined with reflection, had increased participants' self-knowledge, although naming emotions and expressing them - which here meant saying something about them aloud- was considered difficult. Naming emotions had made participants feel more vulnerable, and it had not been easy for them to admit that not all of their emotions were positive. Despite this, this scenario was found to increase confidence and open interaction.

\subsection{EI and situational awareness}

The topic for scenario 3 was regulation of one's emotions and awareness of other people's emotions. According to the respondents, the scenario was useful for increasing skills related to EI, interaction, recognition of one's temperament, situational awareness and anticipation. The development of self-control and better control of emotions were mentioned as one result of the simulated training. The participants found it surprising that a great variety of emotions could emerge in the one and same situation, depending on participant roles and previous experiences. The observation was made that frequently, another person's mood may be contagious. The respondents reflected on how becoming aware of their own and other people's emotions might affect the shared, collective space and atmosphere. They also observed that a team member's stress and worry might cause lack of concentration and hinder fast-paced, effective teamwork. According to the participants, situational awareness is difficult, if a person is exhausted or extremely stressed.

The participants indicated that the learning experience had been intense. They literally sighed after the scenarios, when they were able to step down from the roles. On the other hand, they found that the scenarios and the debriefing, that is discussion and joint reflection on the roles, can be useful as a form of work supervision.

\section{Discussion}

EI and situational awareness are elusive concepts. They are thought to have both cognitive and emotional components and they have been linked to the trait/ability discussion. It seems unlikely that EI and SA could be learnt through studying literature alone. The development of EI and SA requires experiential methods, such as simulation and contextualized learning, combined with reflection.

The participants to this study, mental health and child protection professionals in SMEs, found simulation coaching an effective method for learning EI, situational awareness and teamwork skills. As noted earlier, simulation can increase teamwork and interprofessional communication skills ${ }^{[52]}$ and $\mathrm{SA}^{[33]}$ - all essential attributes for good quality client care and safety. The participants also reported that the simulation coaching could be seen as a form of work supervision.

Reflection has been identified as an essential element in the process of developing such non-technical skills as EI and SA. According to the participants of this study, simulation coaching can offer an opportunity to experientially look at one's daily work and reflect on the associated emotions and thoughts. As has been said before in research, shared reflection only becomes possible if an open and accepting atmosphere is created and confidentiality secured; any sensitive or private material should not be discussed after ending the coaching sessions. In addition to shared reflection, a safe atmosphere fosters creativity and critical thinking. ${ }^{53]}$ The feedback and reflection sessions following scenarios can, at best, bring up concrete development needs and result in wider perspectives, in more uniform or alternative practices, or in meaningful innovations.

The more digital and automated the world of work becomes, the more important is to foster human interaction and team intelligence. ${ }^{[54]}$ If collaboration at workplaces succeeds, more of each team member's potential is brought together, so that team intelligence and collective situational awareness can evolve and be targeted at reaching shared objectives.

\section{Conchusions}

Based on the results, it can be said that simulation coaching offers potential for the development of EI and situational awareness in mental health and child protection professionals. Simulation coaching can also be considered a form of work supervision, which provides an opportunity for collegial sharing and reflection.

The results of this study can be useful for various continuing education contexts in health and social services, but also for initial health and social care education. Examples of potential target groups for simulation coaching on EI and SI involve early intervention teams in mental health services, early childhood educators and teaching staff in primary and secondary education.

\section{CONFlicts OF InTEREST Disclosure}

The authors declare they have no conflicts of interest. 


\section{REFERENCES}

[1] Seinäjoki University of Applied Sciences. 2020. Available from: https://www.seamk.fi/en/

[2] Sedu Education and Training. 2020. Available from: https://www . sedu.fi/en

[3] Merriam-Webster Dictionary. 2020. Available from: https://www . merriam-webster.com/dictionary/emotion

[4] Goleman D. Emotional intelligence. New York: Bantam Books; 1995.

[5] Cherry K. The everything psychology book 2nd Ed. USA: Adams Media; 2010.

[6] Saloney P, Mayer JD. Emotional intelligence. Imagin Cogn Pers. 1990; 9(3): 185-211. https://doi .org/10.2190/DUGG-P24E-5 $2 \mathrm{WK}-6 \mathrm{CDG}$

[7] Lievens F, Chan D. Practical intelligence, emotional intelligence, and social intelligence. In J L Farr, NT Tippins (Eds.), Handbook of employee selection Routledge/Taylor \& Francis Group; 2010. 339-359 p.

[8] Salovey P, Brackett MA, Mayer JD. Emotional intelligence: key readings on the Mayer and Salovey Model. National Professional Resources Inc.: Dude Publishing; 2004.

[9] Mayer JD, Salovey P, Caruso DR, et al. Measuring emotional intelligence with the MSCEIT V2.0. Emotion. 2003 Mar; 3: 97-105. PMid: 12899321. https://doi.org/10.1037/1528-3542.3.1.97

[10] Bar-On R. The Bar-On model of emotional-social intelligence. Psicothema. 2006; 18 Suppl: 13-25. Available from: https://www.researchgate.net/publication/6509274_T he_Bar-On_Model_of_Emotional-Social_Intelligence

[11] Cherniss C. Emotional intelligence: toward clarification of a concept. Ind Organ Psychol. 2010; 3: 110-26. https://doi.org/10.111 $1 / j .1754-9434.2010 .01231 . x$

[12] Mayer JD, Salovey P, Caruso DR. Models of emotional intelligence. In R. J. Sternberg (Ed.), Handbook of intelligence. 2nd ed. New York: Cambridge University Press; 2000. 396-420 p. https://doi.org/10.1017/CB09780511807947.019

[13] Freshwater D, Stickley T. The heart of the art: emotional intelligence in nurse education. Nurs Inq. 2004; 11(2): 91-8. PMid: 15154888. https://doi.org/10.1111/j.1440-1800.2004.00198.x

[14] McQueen ACH. Emotional intelligence in nursing work. J Adv Nurs. 2004; 47(1): 101-8. PMid: 15186473. https://doi.org/10.111 $1 / j .1365-2648.2004 .03069 . x$

[15] Akerjordet K, Severinsson E. Emotional intelligence: a review of the literature with specific focus on empirical and epistemological perspectives. J Clin Nurs. 2007; 16(8): 1405-16. PMid: 17655529. https://doi.org/10.1111/j.1365-2702.2006.01749.x

[16] Akerjordet K, Severinsson E. The state of the science of emotional intelligence related to nursing leadership: an integrative review. J Nurs Manag. 2010 May; 18(4): 363-82. PMid: 20609041. https://doi.org/10.1111/j.1365-2834.2010.01087.x

[17] James I, Andershed B, Gustavsson B, et al. Emotional knowing in nursing practice: in the encounter between life and death. Int $\mathrm{J}$ Qual Stud Health Well-being. 2010; 5(2): 1-15. PMid: 20640014. https://doi.org/10.3402/qhw.v5i2.5367

[18] Stamer K. Teaching strategies to increase emotional intelligence: do they make a difference in online RN-BSN students? 2017. Available from: https://doi.org/10.2139/ssrn. 2995058

[19] Imani B, Kermanshahi SMK, Vanaki Z, et al. Iranian hospital nurses' lived experiences of emotional intelligence: a phenomenological study, Issues Ment Health Nurs. 2018; 40(8): 712-9. PMid: 29851528. https://doi.org/10.1080/01612840.2017.1395497
[20] Karimi L, Leggat SG, Bartram T, et al. The effects of emotional intelligence training on the job performance of Australian aged care workers. Health Care Manage Rev. 2020; 45(1): 41-51. PMid: 29742522. https://doi.org/10.1097/HMR.0000000000000200

[21] Kooker MB, Shoultz J, Codier EE. Identifying emotional intelligence in professional nursing practice. J Prof Nurs. 2007; 23(1): 30-6. PMid: 17292131. https://doi.org/10.1016/j.profnu rs.2006.12.004

[22] Akerjordet K, Severinsson E. Emotional intelligence in mental health nurses talking about practice. Int J Ment Health Nurs. 2004; 13: 164 70. PMid: 15361171. https://doi.org/10.1111/j.1440-097 9.2004.0328.x

[23] Feather R. Emotional intelligence in relation to nursing leadership: does it matter? J Nurs Manag. 2009. PMid: 21456323. Available from: https://doi.org/10.1111/j.1365-2834.2008.00931 . $\mathrm{x}$

[24] Stamer K. Teaching strategies to increase emotional intelligence: do they make a difference in online RN-BSN students? 2017. Available from: https://doi.org/10.2139/ssrn. 2995058

[25] Jean E, Perroux M, Pipin J, et al. How to measure the collective intelligence of primary healthcare teams? Learn Health Syst. Dec 2019. https://doi.org/10.1002/lrh2.10213

[26] Endsley MR. Measurement of situation awareness in dynamic systems. Hum Factors. 1995; 37(1): 65-84. https ://doi .org/10.1 518/001872095779049499

[27] Lowe DJ, Ireland AJ, Ross A, et al. Exploring situational awareness in emergency medicine: developing a shared mental model to enhance training and assessment. Postgrad Med. Nov 2016; 92(1093): 653-8. PMid: 27129912. https ://doi .org/10.1136/postgrad medj-2015-133772

[28] Smith K, Hancock P A. Situation awareness is adaptive, externally directed consciousness. Hum Factors. 1995; 37(1): 137-48 https://doi.org/10.1518/001872095779049444

[29] Busby S, Witucki-Brown J. Theory development for situational awareness in multi-casualty incidents. J Emerg Nurs. 2011; 37(5): 444-52. PMid: 21889652. https://doi.org/10.1016/j.jen. 2010.07 .023

[30] Fore AM, Sculli GL. A Concept Analysis of Situational Awareness in Nursing. J Adv Nurs. 2013; 69(12): 2613-21. PMid: 23528125. https://doi.org/10.1111/jan.12130

[31] Chapman LRM, Molloy L, Wright F, et al. Implementation of situational awareness in the pediatric oncology setting. Does a 'huddle' work and is it sustainable? J Pediatr Nurs. 2019; 50: 75-80. PMid: 31770680. https://doi.org/10.1016/j.pedn.2019.10.016

[32] Rosenman ED, Dixon AJ, Webb JM, et al. A simulation-based approach to measuring team situational awareness in emergency medicine: a multicenter, observational study. Acad Emerg Med. 2018; 25(2): 196-204. PMid: 28715105. https://doi.org/10.1111/ acem. 13257

[33] Gregory A, Hogg G, Ker J. Innovative teaching in situational awareness. Clin Teach 2015; 12: 1-5. PMid: 26059914. https: //doi.org/10.1111/tct. 12310

[34] Fågel J, Terämä M. Autenttisen oppimiskokemuksen mahdollistaminen verkko-opetuksessa [Authetic learning experience in online teaching, in Finnish] [Bachelor Thesis]. Tampere University of Applied Sciences, Vocational Teacher Education, Finland; 2011. 32 p.

[35] Cook DA, Hatala, R, Brydges R, et al. Technology-enhanced simulation for health professions education: a systematic review and meta-analysis. JAMA. 2011; 306(9): 978-88. PMid: 21900138. https://doi.org/10.1001/jama.2011.1234

[36] Linder LS, Pulsipher N. Implementation of simulated learning experience for baccalaureate pediatric nursing students. Clin Simul Nurs. 
2008; 3: 41-7. https://doi.org/10.1016/j.ecns.2008.09.0 02

[37] Alinier G. A typology of educationally focused medical simulation tools. MediTeach. 2007; 29(8): e243-50. PMid: 18236268. https://doi.org/10.1080/01421590701551185

[38] Rodgers B, Adamson K, Jeffries, P. NLN Jeffries Simulation Theory: brief narrative description. Nurs Educ Perspect. 2015; 36: 292 3. PMid: 26521496. https://doi.org/10.1097/00024776-2 01509000-00004

[39] Duff B. Creating a culture of safety by coaching clinicians to competence. Nurse Educ Today. 2013; 33(10): 1108-11. PMid: 22726347. https://doi.org/10.1016/j.nedt.2012.05.025

[40] Forneris SG, Neal DO, Tiffany J, et al. Enhancing clinical reasoning through simulation debriefing: a multisite study. Nurs Educ Perspect. 2015; 36(5): 304-10. PMid: 26521499. https://doi.org/10.5 480/15-1672

[41] Cohen BS, Boni R. 2018. Holistic nursing simulation: a concept analysis. J Holist Nurs. 2018; 36(1): 68-78. PMid: 27895209. https://doi.org/10.1177/0898010116678325

[42] Salminen-Tuomaala M, Paavola K, Paussu P. Health and social care leaders' self-rated competence and learning needs in small and medium-sized enterprises. Clin Nurs Stud. 2019; 7(2): 62-70. https://doi.org/10.5430/cns.v7n2p62

[43] Salminen-Tuomaala M, Hallila J, Niinimäki A, et al. The simulation coaching concept - a step towards expertise. J Nurs Educ Pract. 2020; 10(4): 83-90. https ://doi.org/10.5430/jnep.v10n4p83

[44] Decker S, Fey M, Sideras S, et al. Standards of best practice: Simulation Standard VI: the debriefing process. Clin Simul Nurs. 2013; 9(6 Suppl.): S27-9. https://doi.org/10.1016/j.ecns. 2013. 04.008

[45] Sittner BJ, Aebersold ML, Paige JB, et al. INACSL Standards of Best Practice for simulation: past, present, and future. Nurs Educ Perspect.
2015; 36: 294-8. PMid: 26521497. https ://doi.org/10.5480/ 15-1670

[46] Dunderfelt T. Läsnäoleva kohtaaminen. PS-kustannus [Presence in encounters, in Finnish]: PS-kustannus; 2016.

[47] Elo S, Kyngäs H. The qualitative content analysis process. J Adv Nurs. 2008; 62: 107-15. PMid: 18352969. https ://doi.org/10 $.1111 / j .1365-2648.2007 .04569 . x$

[48] TENK Finnish Advisory Board on Research Integrity Responsible conduct of research and procedures for handling allegations of misconduct in Finland. 2012. (In Finnish, Swedish and English). Available from: https://www.tenk.fi/files/HTK_ohje_2013.pd f

[49] Burns N, Grove S. The practice of nursing research. Appraisal, synthesis and generation of evidence. 6th ed. Missouri: Saunders Elsevier; 2009.

[50] Graneheim UH, Lundman B. Qualitative content analysis in nursing research: concepts, procedures and measures to achieve trustworthiness. Nurse Educ Today. 2004; 24(2): 105-12. PMid: 14769454 https://doi.org/10.1016/j.nedt.2003.10.001

[51] Holloway I, Wheeler S. Qualitative research in nursing and healthcare. 3rd ed. West Sussex: Wiley-Blackwell; 2010.

[52] Mager DR, Lange JW, Greiner PA, et al. Using simulation pedagogy to enhance teamwork and communication in the care of older adults: The ELDER project. J Contin Educ Nurs. 2012; 43(8): 363 9. PMid: 22715874. https://doi.org/10.3928/00220124-2 0120615-52

[53] Keskitalo T. Developing a pedagogical model for simulation-based healthcare education. [Dissertation]. Acta Electronica Universitatis Lapponiensis 167. Rovaniemi, Finland: University of Lapland; 2015.

[54] Hiila I, Tukiainen M, Hakola I. Tiimiäly, opas muuttuvaan työelämään. [Team intelligence, a guide for the changing world of work, in Finnish]. Keuruu, Finland: Otavan Kirjapaino Oy; 2019. 